\title{
RECENT RESERVOIR AGES FOR DANISH FJORDS AND MARINE WATERS
}

\author{
SUSANNE HEIER-NIELSEN,,$^{1,2}$ JAN HEINEMEIER ${ }^{1}{ }^{H}$ H. L. NIELSEN ${ }^{1}$ and NIELS RUD ${ }^{1}$
}

\begin{abstract}
AMS ${ }^{14} \mathrm{C}$ dates were measured for 28 mollusk shells collected live in Danish waters over the period AD 1885 to 1945 . Fourteen samples were from fjords and 14 were marine samples from the Danish Skagerrak-Kattegat coastal area and from the Belts. Reservoir ages were calculated for all samples on the basis of the tree-ring calibration curve. For the marine samples, which cover the period $A D 1885-1916$, we found a weighted-average reservoir age of $377 \pm 16 \mathrm{yr}$. The marine $\Delta R$ values (the difference between the measured ${ }^{14} \mathrm{C}$ age and the age deduced from marine, mixed-layer model calculation of Stuiver, Pearson and Braziunas (1986)) were found to be uniform within the experimental uncertainty with a weighted average of $\Delta R=13 \pm 16 \mathrm{yr}$. Based on the observed scatter, the standard deviation is $21 \mathrm{yr}$. This result shows that it is justified to use the marine calibration curve with standard parameters $(\Delta R=0)$ when ${ }^{14} \mathrm{C}$-dating marine samples from the Danish area. Our value is consistent with the result $\Delta R=-33 \pm 27 \mathrm{yr}$ previously found for the Norwegian and Swedish Skagerrak-Kattegat coasts. In contrast, reservoir ages for Danish fjords were found to vary from 400 to $>900 \mathrm{yr}$, far beyond experimental uncertainty. We ascribe this to varying content of dissolved, old soil carbonate (hard-water effect). Therefore, dating of samples from such fjord environments is expected to be uncertain by several hundred years.
\end{abstract}

\section{INTRODUCTION}

The aim of the present paper is to provide more data on reservoir ages for Danish sea and fjord waters. This information is needed to correct the measured conventional ${ }^{14} \mathrm{C}$ dates obtained for marine archaeological and geological samples from this region for the reservoir effect. The marine reservoir age $R(t)$ is defined as the difference between the measured ${ }^{14} \mathrm{C}$ age of a marine sample collected in calendar year $t$ and the atmospheric ${ }^{14} \mathrm{C}$ age as taken from the tree-ring record for the same year. As indicated by the notation, the reservoir age $R(t)$ for a given location is expected to vary with time, reflecting the difference between the wiggles on the tree-ring curve and the smoothed wiggles in the slowly responding ocean curve.

Stuiver, Pearson and Braziunas (1986) calculated a smooth calibration curve for the mixed layer of a model ocean. To accommodate local effects in the actual oceans, they introduced the quantity $\Delta R$, defined as the difference between the measured sample age and the global model curve. The quantity $\Delta \mathrm{R}$ for a given region is expected to be constant in time to a first approximation, to the extent that the regional reservoir, from which the sample is taken, parallels the global marine model. Radiocarbon laboratories handle the correction for reservoir effect in different ways. A widely used first-order approximation is to replace $R(t)$ by a constant (regional) value, $R^{*}$. This fixed reservoir correction, $\mathrm{R}^{*}$, is subtracted from the measured ${ }^{14} \mathrm{C}$ age before the atmospheric (tree-ring) calibration curve is used to obtain the calibrated age. However, a more accurate procedure is to subtract $\Delta R$ from the measured age and use the marine calibration curve. This procedure was introduced by Stuiver, Pearson and Braziunas (1986) following a suggestion by Olsson (1980).

Stuiver, Pearson and Braziunas (1986) and Stuiver and Braziunas (1993) compiled reservoir age measurements from various regions and mapped the geographical variations of $\Delta R$. In their model for the mixed layer, $\Delta R=0$ corresponds to $R(t)=402 \mathrm{yr}$ in the year $A D 1830$. The value $400 \mathrm{yr}$ is extensively used as a standard reservoir correction, $\mathrm{R}^{*}$, for the North Atlantic region (e.g., Bard 1988), although the model calculations show frequent excursions on the order of 50-100 yr from this value in the past. Special considerations apply in regions that are not expected to parallel the global model. For example, for a fjord-like environment, one would expect a highly variable reservoir age due to limited mixing with the world ocean, short time constant in exchange with the atmo-

\footnotetext{
${ }^{1}$ AMS ${ }^{14} \mathrm{C}$ Dating Laboratory, Institute of Physics and Astronomy, University of Aarhus, DK-8000 Aarhus C, Denmark
} ${ }^{2}$ Department of Earth Sciences, University of Aarhus, DK-8000 Aarhus C, Denmark 
sphere and possibly hard-water effects. Results of such effects have been observed for estuarine environments (Long Island Sound) where reservoir ages significantly higher than the regional marine value are recorded (E. Little, quoted in Stuiver and Braziunas 1993; Dye 1994). Information on reservoir effects in Danish fjord-like areas is important, as prehistoric settlements were often established in this kind of sheltered coastal environment.

In this study, we present accelerator mass spectrometry (AMS) ${ }^{14} \mathrm{C}$ dates for 28 mollusk shells collected live at known historic times over the period $\mathrm{AD}$ 1885-1945, avoiding post-1950 samples influenced by nuclear tests. Fourteen samples were from Danish fjords, mainly the Limfjord, and 14 were marine samples from the Skagerrak-Kattegat area and from the Danish Belts.

\section{Collection Sites}

The mollusk shells, believed to have been collected live, were provided by two Danish museums. The samples had been stored dry since the time of collection. Most samples (25) are from the Museum of Zoology, University of Copenhagen and 3 are from the Museum of Natural History, University of Aarhus. For each sample, information about species, collection date and site and water depth was available (Fig. 1). We distinguish between marine and fjord-like environments. The term fjord in Denmark covers inlets in lowland surroundings as opposed to, e.g., Norwegian highland fiords. The samples representing marine environment were collected in the Skagerrak-Kattegat area and in the Danish Belts. The samples from fjord-like environments were collected in four Danish fjords, 11 from the Limfjord and one from each of Randers Fjord, Horsens Fjord and Roskilde Fjord. The three latter fjords are long, narrow inlets with a mixture of riverine freshwater and sea water. The Limfjord is a sound connecting the North Sea and the Kattegat across the peninsula of Jutland. The main current direction in the Limfjord is from the west to the east; hence, there is a net input of marine North Sea water (ca. 33\%o salinity) and a net output of less saline (ca. 27\%o) water to the Kattegat (Limfjordskomiteen 1976). In the past, the Limfjord has been intermittently closed off from the North Sea, the last closed period ended in $\mathrm{AD}$ 1825. Part of the freshwater input to the fjords is groundwater runoff which is expected to be low in ${ }^{14} \mathrm{C}$, as groundwater from the regions considered in this paper contains dissolved, old soil carbonate (hard-water effect). Further, the water may have acquired a considerable age during seepage to the streams.

\section{METHODS}

The shell samples were treated following the standard mollusk rinsing procedure (e.g., Andersen 1968). To eliminate any possible surface contamination, the outer $25 \%$ of the shell was removed by etching in $1 \mathrm{M} \mathrm{HCl}$. Any organic carbon incorporated in the shell carbonate was removed by treatment with a $\mathrm{KMnO}_{4}$ solution for $16-20 \mathrm{~h}$ at $80^{\circ} \mathrm{C}$. The $\mathrm{CO}_{2}$ was liberated with $\sim 100 \%$ phosphoric acid in an evacuated vial at $25^{\circ} \mathrm{C}$. Part of the $\mathrm{CO}_{2}$ was used for $\delta^{13} \mathrm{C}$ measurements; the rest was converted to graphite for AMS ${ }^{14} \mathrm{C}$ measurements by reduction with $\mathrm{H}_{2}$, with cobalt as a catalyst. A small reaction volume and a high initial pressure of the reacting gases was used (Vogel et al. 1984).

All ${ }^{14} \mathrm{C}$ measurements were performed on the Aarhus EN tandem accelerator (Andersen et al. 1989) and the $\delta^{13} \mathrm{C}$ measurements were performed on the mass spectrometer at Science Institute, Reykjavík. The quoted uncertainties on the ${ }^{14} \mathrm{C}$ dates are based on ion-counting statistics. A series of ${ }^{14} \mathrm{C} /$ ${ }^{13} \mathrm{C}$ measurements with statistical uncertainties of $0.25-0.75 \%\left(20-60{ }^{14} \mathrm{C} \mathrm{yr}\right)$ submitted to the Third International Radiocarbon Intercalibration (TIRI) indicate that this is the dominant source of error. The dating results are given as conventional ${ }^{14} \mathrm{C}$ ages in years $\mathrm{BP}$ (before 1950), based on the measured ${ }^{14} \mathrm{C} /{ }^{13} \mathrm{C}$ ratio corrected for the natural isotopic fractionation by normalizing the result to the standard $\delta^{13} \mathrm{C}$ value of -25\%o PDB (Stuiver and Polach 1977; Andersen et al. 1989). 


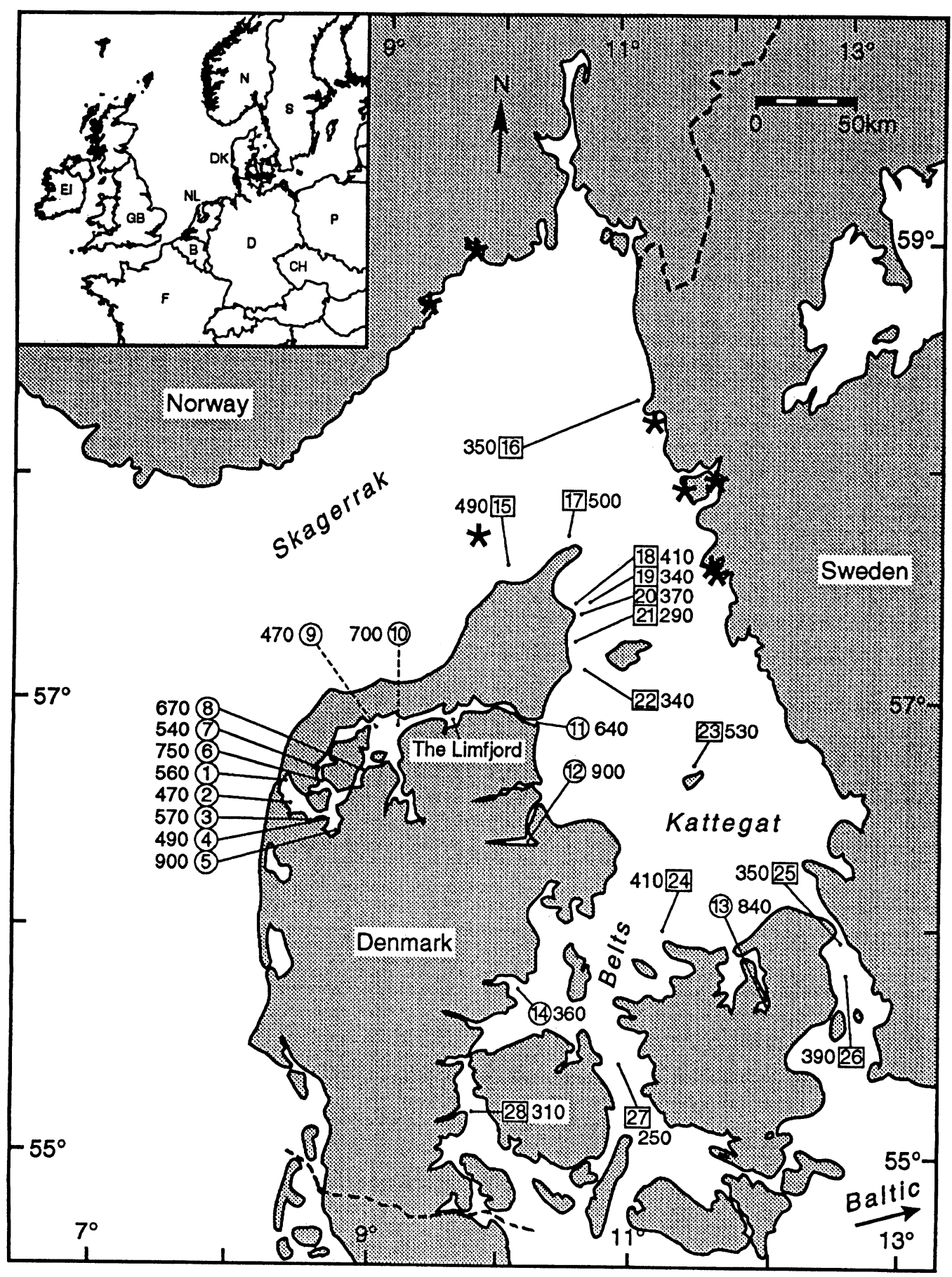

Fig. 1. Map of investigation area with site numbers (see Tables 1 and 2 ) and reservoir ages $R(t)$. Site numbers in circles represent fjord samples; those in squares represent marine samples. Numbers represent a progression in site location from the North Sea towards the Baltic Sea. Uncertainties on $R(t)$ values are generally $60-80 \mathrm{yr}$. The eight sites marked with an asterisk refer to the survey given by Stuiver, Pearson and Braziunas (1986). 


\section{RESULTS}

The ${ }^{14} \mathrm{C}$ dates and the $\delta^{13} \mathrm{C}$ values are given in Table 1 (fjord samples) and Table 2 (marine samples) along with all information available for the dated samples. The measured ages for the marine samples are plotted in Figure 2 against year of collection and compared with the terrestrial and marine calibration curves. No correction is necessary for the short biological life span $(<5 \mathrm{yr})$ of the dated specimens. For each sample, we have calculated the corresponding reservoir age $R(t)$ as the difference between the measured ${ }^{14} \mathrm{C}$ age and the (interpolated) terrestrial calibration curve (Stuiver and Reimer 1993) based on 20-yr samples of tree rings. The results are displayed in Figure 3. Using the mixed-layer marine model of Stuiver and Braziunas (1993), we also calculate the $\Delta R$ values, i.e., the sample age deviations from the marine calibration curve. Both the $R(t)$ and the $\Delta R$ values are listed in Tables 1 and 2.

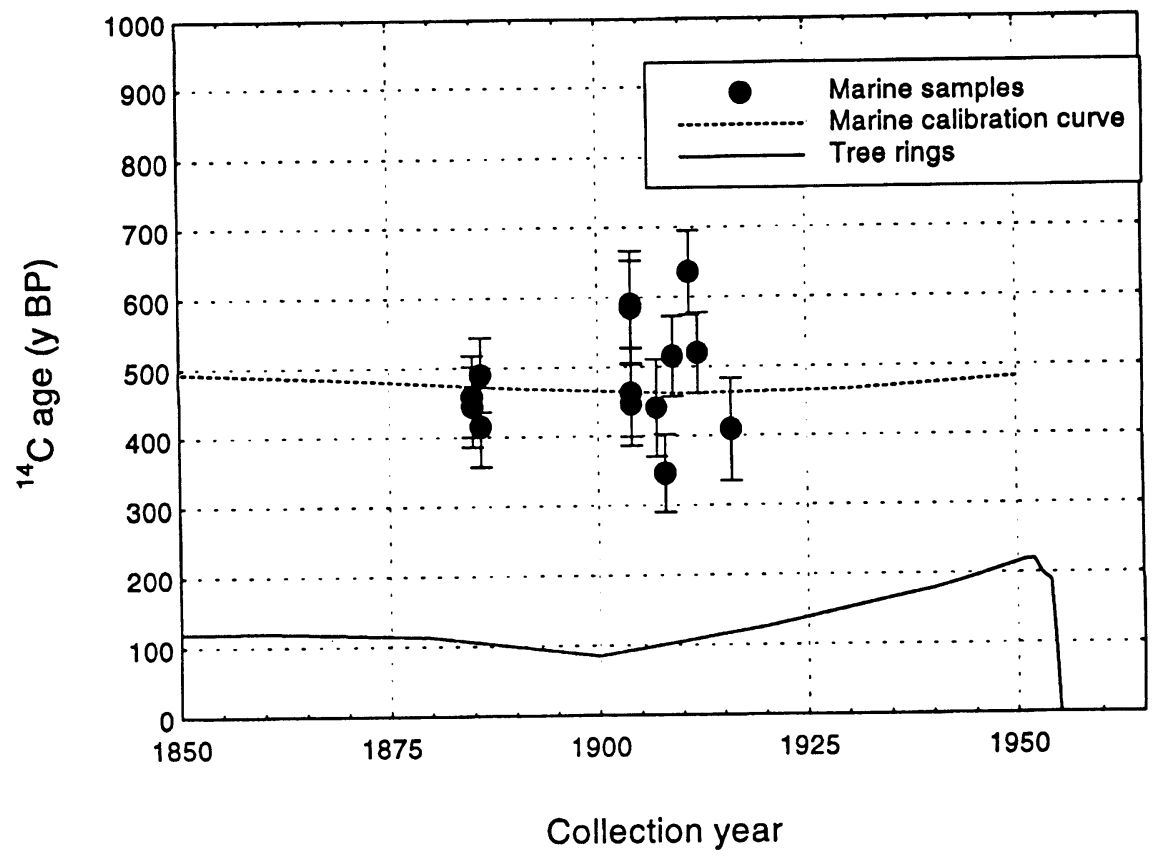

Fig. 2. Conventional ${ }^{14} \mathrm{C}$ ages for the 14 marine shell samples (Table 2) plotted vs. year of collection. The solid curve shows the terrestrial calibration curve (Stuiver and Reimer 1993). The reservoir age $R(t)$ is the difference between the measured sample age and the terrestrial calibration curve. The dashed curve shows the marine calibration curve for $\Delta R=0$ (Stuiver and Braziunas 1993).

For the 14 marine samples, we calculate the weighted mean $R(t)$ at $377 \pm 16 \mathrm{yr}$. It is meaningful to calculate this quantity because the samples belong to a time interval where the marine model calculations show very little variation in $R(t)$, as seen in Figure 2 . We calculate the weighted mean $\Delta R$ at $13 \pm 16 \mathrm{yr}$. The scatter $\sigma$ (empirical standard deviation) of the unweighted mean of the data set of $\Delta \mathrm{R}$ is $21 \mathrm{yr}$, i.e., only 1.3 times the measuring uncertainty. Like Stuiver, Pearson and Braziunas (1986) we conclude that the additional uncertainty in $\Delta \mathrm{R}$ introduced by non-uniform ${ }^{14} \mathrm{C}$ content of this regional ocean reservoir is small. We treat the whole area as one marine region, although there is a slight tendency for the $\Delta R$ values to decrease from Skagerrak through Kattegat. Samples from deep waters in Skagerrak (sites no. 15 and 17) have $\Delta R$ values higher than the average, which could 
reflect the more pronounced influence of North Atlantic waters in this part of the region. Conversely, samples from the southern part of the Belts near the Baltic Sea (sites no. 27 and 28) have $\Delta R$ values lower than the average, in accordance with the fact that low $\Delta R$ values have been found for the Baltic (G. Possnert, personal communication 1995). However, the present data points are too few to allow us to draw such hydrographical conclusions.

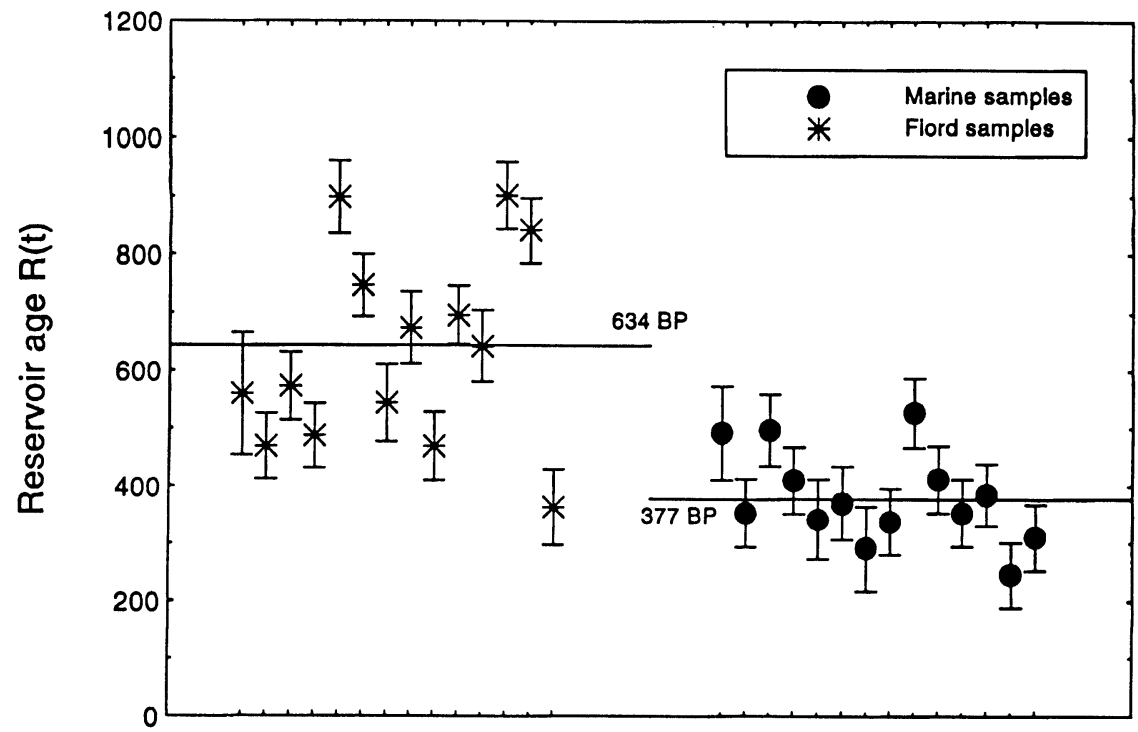

$123456789101214 \quad 16182022242628$

Site number

Fig. 3. Reservoir ages $R(t)$ for all samples. Separate weighted mean values are indicated for fjord and marine samples. Site numbers represent a progression in site location from the North Sea toward the Baltic Sea.

In contrast to the marine samples, the $R(t)$ values of the 14 fjord samples, of which 11 are from the Limfjord, show a large natural variability with a standard deviation of $170 \mathrm{yr}$. This spread is about three times the typical measuring uncertainty (see Fig. 3). The mean value is $634 \mathrm{yr}$, which is much higher than for the marine reservoir ages. The corresponding $\Delta \mathrm{R}$ values range from 82 to $554 \mathrm{yr}$ with a mean of $279 \mathrm{yr}$. As this variability also by far exceeds the expected time variation, we conclude that the investigated fjord areas are not part of a uniform ${ }^{14} \mathrm{C}$ reservoir. Thus, the $\Delta \mathrm{R}$ concept loses its meaning in this case. Only one $\Delta \mathrm{R}$ value has been derived for each of the other three fjords included in this study, but the fact that two out of three of these points deviate considerably from the marine average indicates that the same conclusion applies. The high average value as well as the large geographical variability of the reservoir ages and $\Delta \mathrm{R}$ values for the Limfjord are most likely caused by mixing of the marine-water input from the North Sea with varying amounts of groundwater containing old carbonate from the surrounding land. The following order-of-magnitude calculation supports this explanation: The average salinity of the Limfjord (30\%) compared to the North Sea $(33 \%)$ points to a $10 \%$ dilution of the marine water with freshwater which we assume to be groundwater. The typical groundwater hardness for the Limfjord region corresponds to a bicarbonate concentration about equal to that of North Sea water. Groundwater bicarbonate in temperate zones stems, in most cases, from ${ }^{14} \mathrm{C}$-dead soil carbonate dissolved by an approximately equal molar 

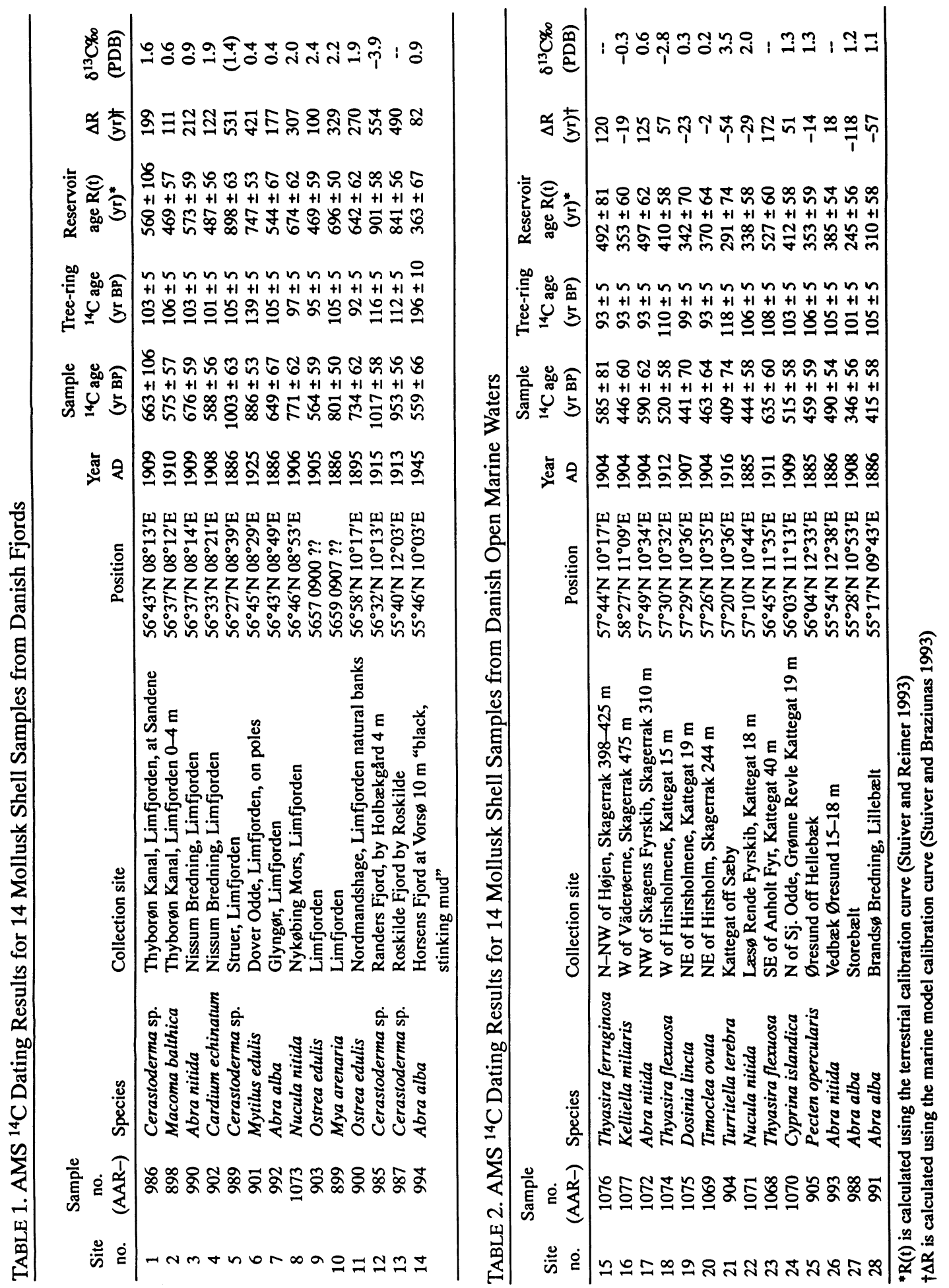
quantity of young soil carbon dioxide resulting in an apparent groundwater ${ }^{14} \mathrm{C}$ age of $c a .5700 \mathrm{BP}$ $(50 \mathrm{pMC})$. Although little is known about the apparent ${ }^{14} \mathrm{C}$ ages of Danish groundwater, preliminary data from this laboratory shows that ages of this order of magnitude are realistic. The mixing of $10 \%$ groundwater of the above age and carbon concentration with North Sea water, known to have an apparent age of $400 \mathrm{yr}$, would thus result in water with an apparent age of $800 \mathrm{yr}$, compatible with our findings for the Limfjord. Note that this calculation applies to present conditions in the Limfjord. In the past, when the fjord was closed to the North Sea, the reservoir ages could have been much higher. It appears that the reservoir effect in the Limfjord depends on the local mixing ratio of waters in a way that is difficult to model. It is not possible to explain the individual data points in terms of hydrological variables since these are largely unknown. As a consequence, all we can say about the reservoir age for a given site in the Limfjord is that it is most probably in the range 400 to $900 \mathrm{yr}$. Even worse, these numbers are expected to be different in the past when the Limfjord was closed to the west. This uncertainty must be considered in the ${ }^{14} \mathrm{C}$ dating of archaeological samples of marine origin from Danish fjord sites.

For the Danish Skagerrak-Kattegat coastal area and the Belts, we have found $\Delta R$ values close to zero, similar to the known $\Delta R$ values for the North Sea and the North Atlantic Ocean. However, one should be careful not to take this as evidence that these connected marine regions form a uniform ${ }^{14} \mathrm{C}$ reservoir, since their hydrographies differ greatly. The reservoir age of a marine reservoir that is in a steady-state carbon-exchange equilibrium with the atmospheric reservoir increases with the marineto-atmospheric reservoir size ratio. Therefore, the reservoir age of a shallow sea like the KattegatBelt area, if viewed as a separate reservoir with a restricted water exchange with the world ocean, is expected to be lower than that of the North Atlantic surface water, simply because of its smaller size. On the other hand, such shallow seas could be influenced from an input of dissolved old carbon from the surrounding land masses leading to a raised apparent age. We cannot rule out that the near-zero $\Delta \mathrm{R}$ value for the Danish marine waters is due to an accidental cancellation of such opposing effects, thus making the resemblance with the $\Delta R$ of the Atlantic Ocean fortuitous. The way to resolve this question would be to investigate the time constant of this reservoir, for example, by measuring its response to the bomb pulse. Work along these lines has been initiated in this laboratory.

\section{Discussion}

A re-evaluation of previous data obtained from shells from the Norwegian-Swedish Skagerrak-Kattegat coasts (Stuiver, Pearson and Braziunas 1986: Table 1) using CALIB 3.0 (Stuiver and Reimer 1993) results in a weighted mean $\Delta R$ value of $-33 \pm 27 \mathrm{yr}$. This is consistent with our result $\Delta R=$ $13 \pm 16 \mathrm{yr}$ for the Danish Skagerrak-Kattegat coastal area. One prebomb sample from southern Kattegat has been reported (K-331) (Krog and Tauber 1974). From this measurement, assuming $\Delta^{13} \mathrm{C}$ $=0 \%$ PDB, we calculate a reservoir age of $\mathrm{R}(\mathrm{t})=238 \pm 64 \mathrm{yr}$ and $\Delta \mathrm{R}=-130 \pm 64 \mathrm{yr}$. The same authors measured three prebomb samples from Danish fjords, 1 from Horsens Fjord and 2 from the Limfjord. The Horsens Fjord sample (K-332) has $\Delta \mathrm{R}=-82 \pm 64 \mathrm{yr}$. The two Limfjord samples (K333 and $\mathrm{K}-433$ ) yield $\Delta \mathrm{R}$ values of $83 \pm 48 \mathrm{yr}$ and $-131 \pm 40 \mathrm{yr}$, respectively. Harkness (1983) investigated the reservoir effect in the coastal environment of the United Kingdom. A recalculation of his results following the convention by Stuiver, Pearson and Braziunas (1986) gave as weighted averages $R(t)=348 \pm 8 \mathrm{yr}$ and $\Delta R=1 \pm 8 \mathrm{yr}$. These results are comparable to our results for the Danish marine waters. 


\section{ConClusion}

On the basis of our results, we can distinguish between two main types of coastal environment, namely the Danish fjords and the open marine areas around Denmark. The reservoir age of the marine areas, the Skagerrak-Kattegat and the Danish belts, resembles that of the North Atlantic and the North Sea, i.e., $\Delta \mathrm{R}=0$. In contrast, we have shown that the average reservoir age of Danish fjords is higher than that of open marine waters. In addition, variability is high, indicating that the investigated fjord areas are not part of a uniform ${ }^{14} \mathrm{C}$ reservoir. We ascribe this variation to varying concentration of dissolved, old soil carbonate from the surrounding land areas.

\section{ACKNOWLEDGMENTS}

We would like to express our sincere thanks to Dr. Tom Schiøtte, Museum of Zoology, Copenhagen, and Dr. Poul Bondesen, Museum of Natural History, University of Aarhus, for placing the mollusk samples at our disposal. The study was financially supported by the Danish Natural Science Research Council.

\section{REFERENCES}

Andersen, B. G. 1968 Glacial geology of Western Troms, North Norway. Norges Geologiske Unders $\emptyset$ kelse 256: 1-160.

Andersen, G. J., Heinemeier, J., Nielsen, H. L., Rud, N., Thomsen, M. S., Johnsen, S., Sveinbjörnsdóttir, A. and Hjartarson, A. 1989 AMS ${ }^{14} \mathrm{C}$ dating on the Fossvogur sediments, Iceland. In Long, A., Kra, R. S. and Srdoc, D., eds., Proceedings of the 13th International ${ }^{14} \mathrm{C}$ Conference. Radiocarbon 31(3): 592-600.

Bard, E. 1988 Correction of accelerator mass spectrometry ${ }^{14} \mathrm{C}$ ages measured in planktonic foraminifera: $\mathrm{Pa}$ leoceanographic implications. Paleoceanography 3 (6): 635-645.

Dye, T. 1994 Apparent ages of marine shells: Implications for archaeological dating in Hawai i. Radiocarbon 36(1): 51-57.

Harkness, D. D. 1983 The extent of natural ${ }^{14} \mathrm{C}$ deficiency in the coastal environment of the United Kingdom. In Mook, W. G. and Waterbolk, H. T., eds., Proceedings of the Symposium ${ }^{14} \mathrm{C}$ and Archaeology. PACT 8: 351-364.

Krog, H. and Tauber, H. 1974 C-14 chronology of lateand postglacial marine deposits in North Jutland. Geological Survey of Denmark, Yearbook 1973: 93-105.

Limfjordskomiteen 1976 Limfjordsundersøgelsen 1973-
75. Samlerapport: $1-67$.

Olsson, I. U. 1980 Content of ${ }^{14} \mathrm{C}$ in marine mammals from northern Europe. In Stuiver, M. and Kra, R., eds., Proceedings of the 10 th International ${ }^{14} \mathrm{C}$ Conference. Radiocarbon 22(3): 662-675.

Stuiver, M. and Braziunas, T. F. 1993 Modeling atmospheric ${ }^{14} \mathrm{C}$ ages of marine samples to $10,000 \mathrm{BC}$. In Stuiver, M., Long, A. and Kra, R. S., eds., Calibration 1993. Radiocarbon 35(1): 137-189.

Stuiver, M., Pearson, G. W. and Braziunas, T. 1986 Radiocarbon age calibration of marine samples back to 9000 cal yr BP. In Stuiver, M. and Kra, R. S., eds., Proceedings of the 12 th International ${ }^{14} \mathrm{C}$ Conference. $\mathrm{Ra}$ diocarbon 28(2B): 980-1021.

Stuiver, M. and Polach, H. A. 1977 Discussion: Reporting of ${ }^{14} \mathrm{C}$ data. Radiocarbon 19(3): 355-363.

Stuiver, M. and Reimer, P. J. 1993 Extended ${ }^{14} \mathrm{C}$ data base and revised CALIB $3.0{ }^{14} \mathrm{C}$ age calibration program. In Stuiver, M., Long, A. and Kra, R. S., eds., Calibration 1993. Radiocarbon 35(1): 215-230.

Vogel, J. S., Southon, J. R., Nelson, D. E. and Brown, T. A. 1984 Performance of catalytically condensed carbon for use in accelerator mass spectrometry. Nuclear Instruments and Methods in Physics Research B5: 289-293. 